:

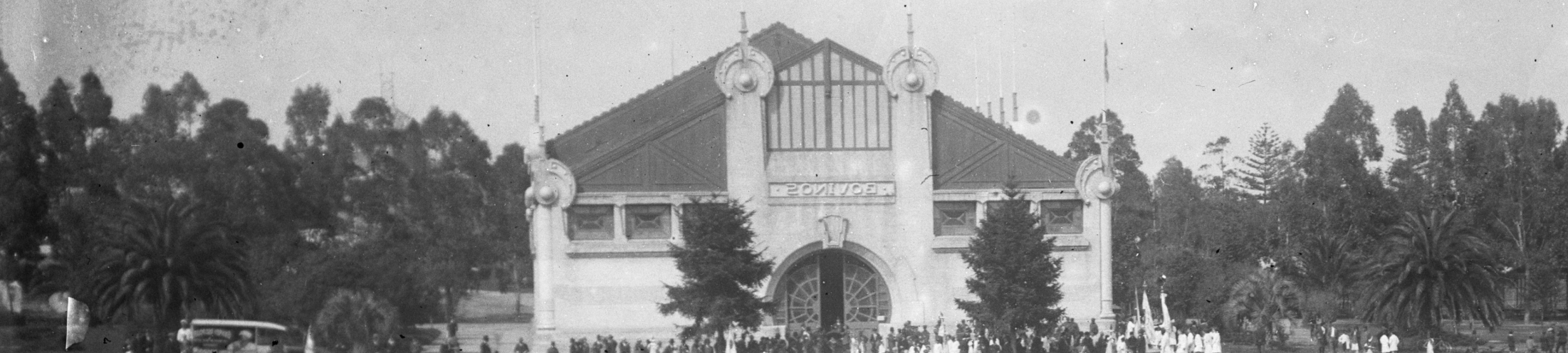

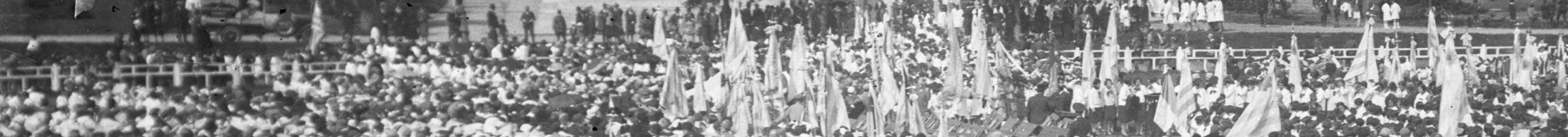

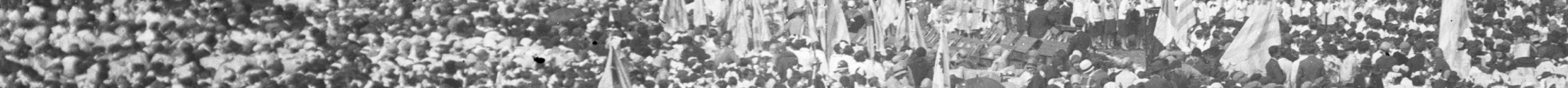

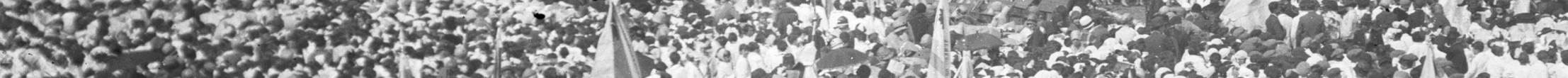

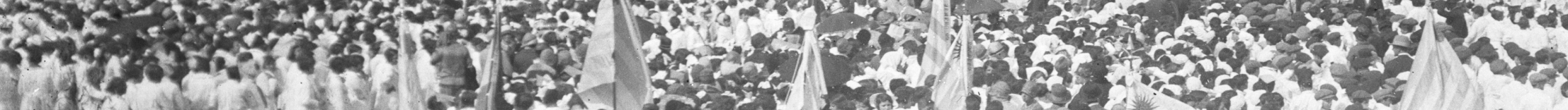

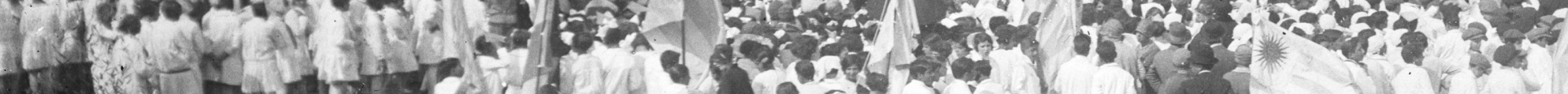

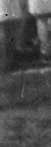
Helniter
is

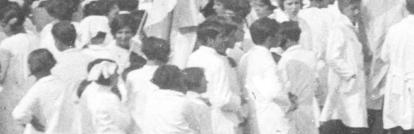
Nin
is
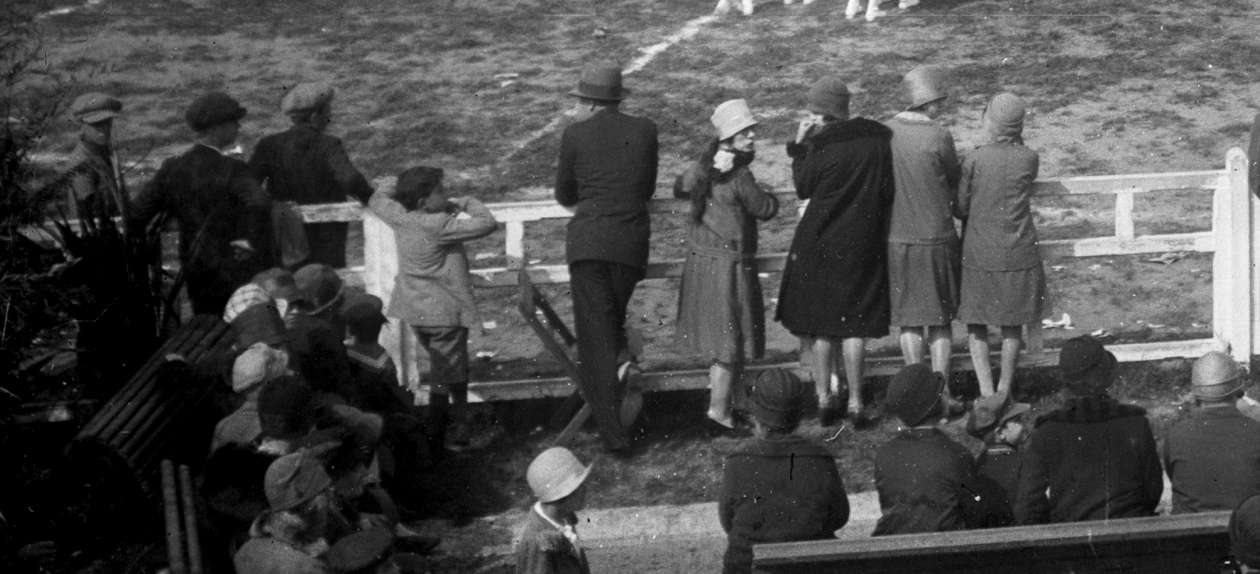
$\frac{2}{2}$ 
Virginia Zabaleta:: Licenciada en Comunicación Social, énfasis en Comunicación Organizacional, por la Universidad Católica del Uruguay. Encargada del Departamento de Comunicación de St. Clare's College, Punta del Este. Ha trabajado en variados proyectos de comunicación interna y externa. Fue directora del

Departamento de Contenidos del sitio web preciolé.es. verdad sentir o comprender lo que su autor quiso transmitir?

Un óleo, una composición musical, una obra de teatro, una representación en danza o incluso la imagen inmortalizada en una fotografía pueden significar mucho. ¿Cómo se explica esto? ¿Cómo puedo afirmar que lo que yo veo tiene un sentido? ¿Y que hay pistas, indicios, mensajes latentes que, en efecto, me hablan de algo? "¿Es que la idea del 'lenguaje' de las imágenes o de las pinturas entendidas como 'textos' es algo más que una metáfora?", se preguntaba Peter Burke en su obra Visto y no visto, el uso de la imagen como documento histórico.

Toda imagen cuenta una historia. Solo hay que prestar atención a los detalles, ver lo oculto detrás de lo obvio, dejar volar la imaginación y, cual si estuviéramos uniendo los puntos de una ilustración para niños, seguir paso a paso el hilo conductor desde una unidad a la otra, hasta lograr comprender el todo.

\section{El punto de partida}

Perdidas entre cajas consumidas por la humedad y comenzando a sentir el trágico efecto de los hongos, cerca de 500 imágenes esperaban ser rescatadas por algún valiente que se propusiera ingresar al abarrotado sótano familiar. Quienquiera que osara atravesar el umbral de la puerta tendría que hacerlo ataviado de mameluco, tapabocas y cuanta barrera antialérgica encontrara en su camino, puesto que el polvo se había alojado en cada rincón del encerrado ambiente, año tras año. Hasta que un día, la puerta se abrió. Finalmente llegó el momento que parecía esquivar el destino, y desde lo alto se oyó una fuerte voz que exclamaba: “¿Las encontraste...? Son unas cajas de cartón, están debajo de los libros de agronomía de tu abuelo... son muy pesadas, tal vez necesites ayuda para subirlas".

Las placas de vidrio que fueron donadas a la Universidad sufrieron una larga espera antes de llegar a nuestras manos. En primer lugar, por su edad: datan de principios del siglo XX. Y en segundo lugar, por el trajín real que implica el transcurso del tiempo para materiales de este tipo, que pasan de mano en mano con cuidados de diversa índole. Propiedad original del Ingeniero Agrónomo Dionisio Garmendia Mujica, padre del Dr. Dionisio Garmendia Bentancourt -quien efectivizó la donación del archivo-, las imágenes integran un variado popurrí donde se aprecian instantáneas de reuniones sociales, eventos deportivos, paisajes rurales, momentos históricos o escenas cotidianas de la vida en la ciudad. Imágenes que pasaron de una generación a la siguiente soportando alguna que otra mudanza para finalmente terminar guardadas en el sótano de una tradicional casona del Prado.

Con el transcurrir de los años, la familia Garmendia Tabares advirtió que si continuaban manteniendo el material en el húmedo sótano donde se encontraba, su estado de conservación sufriría un fuerte deterioro y las fotografías terminarían estropeándose sin vuelta atrás. En ese mismo momento tomaron la decisión de hacer llegar las cajas a la Universidad Católica, donde esperaban se pudiera dar buen destino a las imágenes de su atesorado acervo familiar.

Este cruce de intereses -por un lado, la conservación de un archivo que comenzaba a sufrir las lesiones del tiempo y la humedad y, por el otro, la posibilidad de hacer uso de un fondo particular de imágenes como materia prima para la formación de estudiantes de comunicación, en el proceso de elaboración de sus 


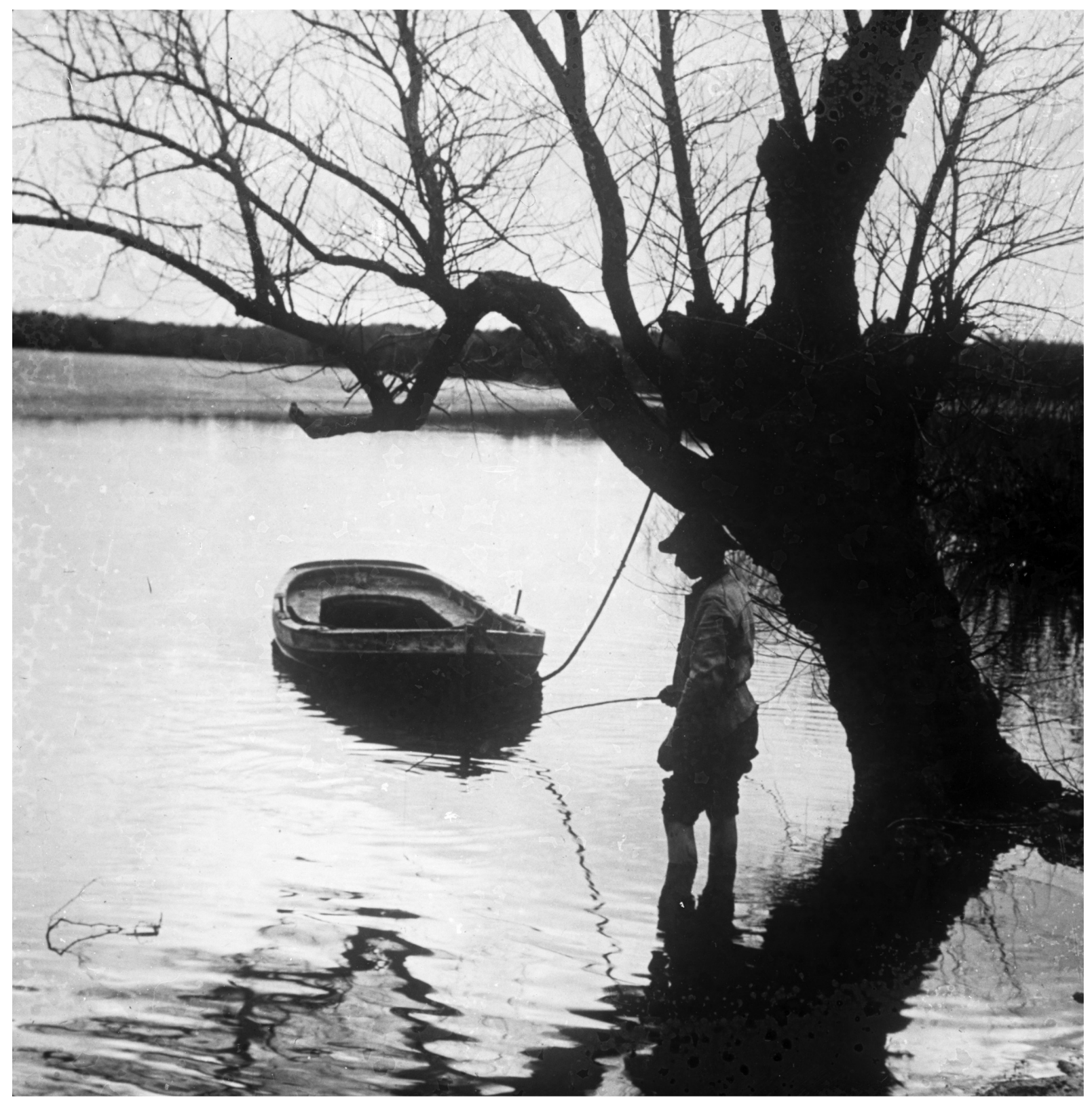

memorias de grado- desencadenó historias paralelas que tomarían su curso en forma ramificada. Un mismo punto de partida, el Fondo Garmendia, dio lugar a investigaciones tan dispares como las imágenes que contenía, de acuerdo a los intereses y a la historia particular de cada estudiante, y a las "posibilidades narrativas" del material encontrado.

Erradicar el analfabetismo visual

El historiador británico Raphael Samuel (1934-1996) se refería a sus contemporáneos y a sí mismo como “analfabetos visuales”. Peter Burke (1937), de igual origen y formación, explica que "en los años cincuenta un niño era y seguiría siendo toda su vida 'pretelevisual' -citando una expresión propia de Samuel-, ya que "su educación, en la escuela y en la universidad, consistía en un adiestramiento en la lectura de textos". Con todo -agrega-, "ya por entonces una minoría significativa de historiadores utilizaba el testimonio de las imágenes, especialmente los especialistas en las épocas en las que los documentos escritos son raros o inexistentes". 


\section{Una ventana abierta al conocimiento autodidacta}

¿Por qué estudiar el pasado única y fundamentalmente en textos escritos por terceros, si podemos incentivar la sed de conocimiento de las nuevas generaciones canalizando su necesidad de estímulos interactivos, su innata capacidad multimedia, su dominio de las múltiples plataformas en línea y redes sociales, su inserción en el e-learning desde la primera infancia, y tantas otras características de una generación que demanda cada vez más y lee cada vez menos, fruto de su propio entorno que hace loas al multitasking?

¿Por qué dar por agotadas las fuentes de conocimiento en determinado tópico cuando se han leído todos los textos académicos que cubren esa temática de interés? ¿Cómo imaginar, estudiar, obtener datos acerca de una realidad lejana en el tiempo o en el espacio, si no existen narraciones que nos la relaten? ¿Nos damos por vencidos?

Una imagen pintada sobre un lienzo, ¿es válida como representación de una realidad desconocida? Interrogantes como ésta dieron lugar a largas discusiones en el ámbito académico, y perduran hasta la actualidad. Sí, existe la posibilidad de que una imagen sea meramente imaginaria 0 no represente fidedignamente el hecho retratado. Sin embargo, con la cada vez más vasta reserva de materiales audiovisuales de la que felizmente se dispone en los museos, reservorios y bibliotecas hoy en día, es más sencillo poder contrastar varias fuentes "alternativas" y así elaborar una especie de collage que me acerque a un retrato lo suficientemente fundado como para darlo por legítimo, o al menos considerarlo una opción más dentro del proceso de conocimiento.
De la misma forma, parece adecuado que el ámbito académico incluya a la fotografía -y a otras manifestaciones, como canciones o pinturas- como fuente válida de investigación, e imparta una metodología de trabajo especialmente aplicada a este tipo de fuentes de información alternativas y complementarias a las tradicionales. No solo a nivel universitario, sino desde las primeras instancias de contacto con la historia y el conocimiento a nivel preescolar, donde es tanto más sencillo aprehender conceptos a través de imágenes. Si se difundiera en todos los niveles de la educación el valor de la información contenida en las imágenes, y se dieran el lugar y el espacio para estudiar y comprender las vías de acercamiento a esta fuente muchas veces ignorada, tendríamos acceso a un testimonio invalorable para estudiar prácticas sociales pasadas, ya que en numerosas ocasiones son el único vestigio que queda de ellas.

En la vecina orilla argentina, por ejemplo, dos arqueólogas provenientes de la Universidad de Buenos Aires

"A partir de fotos antiguas, analizan la cultura de pueblos fueguinos", La Nación, lunes 26 de julio de 2010, Buenos Aires, Argentina. Disponible en http://www.lanacion.com.ar/nota.a sp?nota_id $=1288179$

Op. cit, La Nación, lunes 26 de julio de 2010 . y el Conicet (Consejo Nacional de Investigaciones Científicas y Técnicas) desarrollaron una investigación acerca de los Shelk'nam, los Yamana y los Alakaluf, las tres sociedades nativas que vivieron en la región más austral del mundo. Realizaron el estudio a partir de imágenes tomadas desde el siglo XIX. El proceso de recolección, estudio e interpretación de las fotografías les llevó siete años de trabajo, pero volcó resultados invaluables acerca de culturas de las que muy poco se conocía. "Teniendo en cuenta todo el conocimiento que podía generar ese material visual, la doctora en arqueología Dánae Fiore, investigadora del Conicet y docente de la UBA, y la licenciada en arqueología María Lydia Varela, también de la UBA, tuvieron una idea original: estudiar desde un punto de vista científico un total de 1.131 fotos de los tres pueblos fueguinos -obtenidas principalmente entre 1882 y 1930- como si se tratase de artefactos arqueológicos", indicaba una noticia publicada en el diario La Nación.

"Partiendo de la idea de que esas imágenes -en las que aparecen cuatro mil Shelk'nam, Yamana y Alakalufpodían arrojar conocimiento sobre representaciones y prejuicios de los fotógrafos, como también datos sobre las pautas culturales de esos pueblos originarios, Fiore y Varela hicieron un análisis estadístico de una gran cantidad de datos que incluía características de los individuos (género y edad, entre otros), objetos manipulados, ornamentos y vestimentas usados. Los resultados de la investigación se publican en el libro Memorias de papel (Editorial Dunken)”.

La investigación a partir de fotografías, aunque muy tímidamente, tiene sus primeros adeptos en la región rioplatense y comienzan a apreciarse algunos resultados interesantes. 


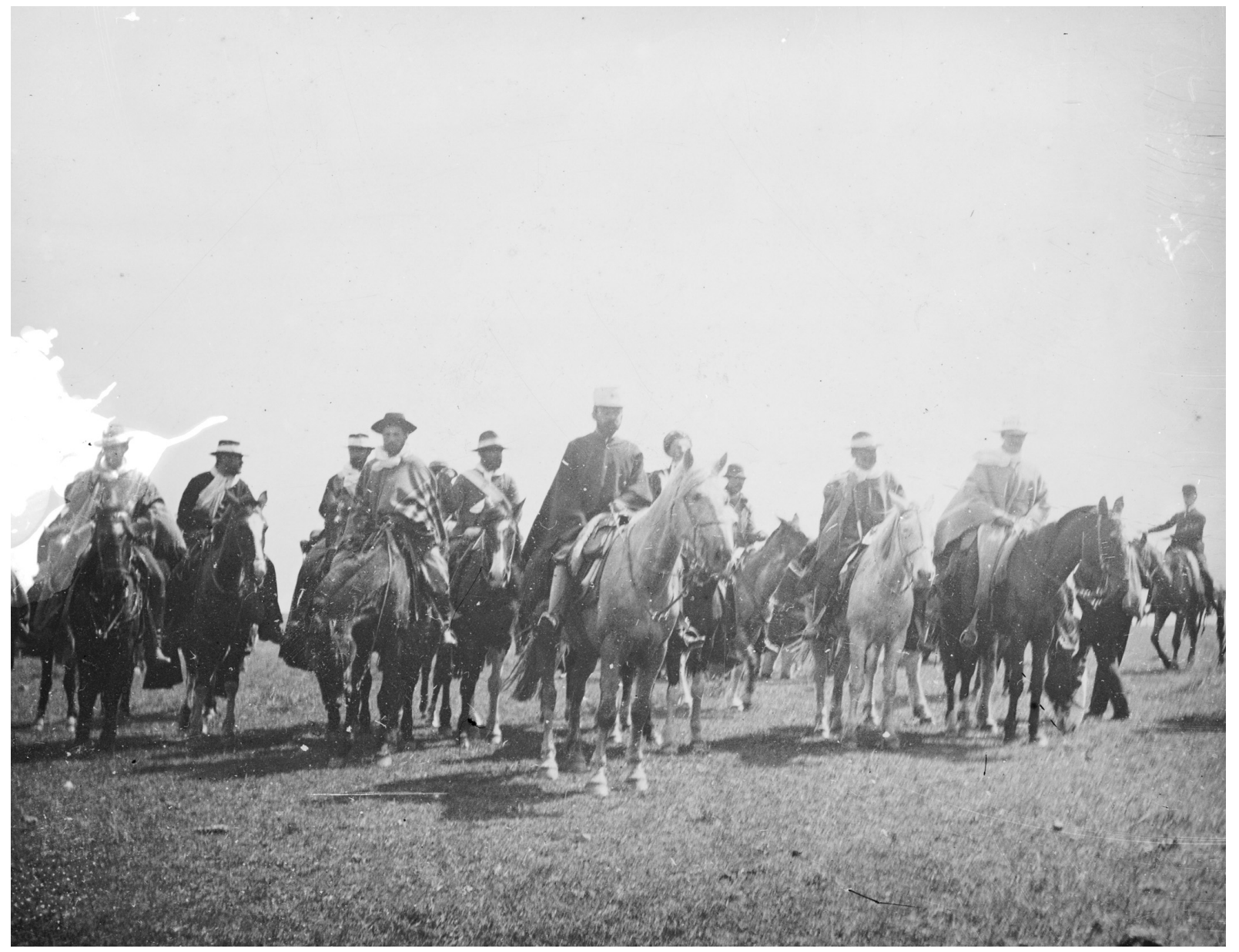

Otro ejemplo es la publicación Cruces - Idas y vueltas de Malvinas de Lorenz y Guembe, un libro de fotografías inéditas tomadas por los propios soldados, que retrataron escenas de su paso por la isla en medio del enfrentamiento del que tan pocas imágenes se conocen. "Las fotos están acompañadas por pequeños textos: fragmentos de libros, informes oficiales, poemas y testimonios de los sobrevivientes entrevistados, apuntes de los autores". "Nos gustó cruzar las fotos con el material ya existente para hacerlos dialogar con las imágenes. Hay materiales muy valiosos, y también queríamos rendir homenaje a los que ya habían recogido testimonios”, dicen Guembe y Lorenz en la nota brindada a la publicación Página/12.

Guembe expresa que "sorprende ver el afán con que algunos ex combatientes y también los familiares de algunos caídos en las islas colectan y guardan fotografías del conflicto. Se trata de lotes de imágenes donde éstas por fin encuentran epígrafes cargados de información, a veces en forma de relatos orales, a veces escritos en el reverso del papel o como título en archivos digitales. (...) Estas son imágenes que se buscan y se guardan para conformar recuerdos, para impedir que se escurran entre las grietas del tiempo. Por eso poco importa la proveniencia de las fotos: todas ellas sirven a este propósito".

Crear y divulgar metodologías de trabajo propias Los motivos que nos pueden llevar a desarrollar investigaciones con fotografías son innumerables. Lo importante es tener los elementos y las herramientas metodológicas para optimizar los recursos y el tiempo del que disponemos.

En el caso uruguayo, los recursos están centralizados en la capital, como es el caso de la Biblioteca Nacional, el CMDF (Centro Municipal de Fotografía) y
$7 \cdot:$

C. Sosa, Página/12, Suplemento Radar, nota de tapa, "La guerra invisible", domingo 11 de marzo de 2007. 8::

M. L. Guembe, No-Retornable. Ver: http://www.no-retornable.com.ar/ v2/dossier/guembe.html 
otros archivos. En el interior del país, faltan espacios de formación en la metodología de trabajo con archivos fotográficos. Se vuelve necesario difundir los procesos de conservación, digitalización y archivo, y estimular, a través de la educación, la apreciación del valor de generar centros municipales o privados dedicados a la conservación de antiguos álbumes familiares y colecciones particulares. Esto sería de gran ayuda para democratizar el acceso al conocimiento y fomentar la construcción de archivos locales, con las debidas precauciones y medidas de conservación que este tipo de material demanda, evitando la pérdida de material que en muchas ocasiones es muy valioso para el estudio de un determinado contexto social o histórico.

El papel de la tecnología también es clave en este sentido, puesto que hoy en día contamos con un aliado importantísimo a la hora de conservar las imágenes sin afectar los originales: el escáner. La digitalización del material disponible en cualquier soporte (vidrio, papel, película fotográfica, etc.) es una herramienta fundamental que tiene muchos beneficios, ya que además de mantener un respaldo a salvo de posibles contingencias externas (hongos, incendios, roturas, roedores, pérdidas) nos da la posibilidad de universalizar el acceso al mismo, a través de redes en línea de forma inmediata, sin necesidad de traslados. Además, es posible la reproducción o impresión del material en el momento deseado, y la restauración digital de imágenes deterioradas.

Pérez Monfort, 1998, p. 10, cit extraída de E. Lara López: Lo fotografía como documento histórico-artístico y etnográfico: una epistemología. Ver http://200.2.12.132/SVI/images/st ories/fotoperiodismo/pdf/lara_I.pdf

A. Frega y L. Betrucci: op. cit. idiomas. Existe una gran necesidad de producción en este sector de la investigación, y sería bueno que a nivel local se pudiera fomentar su creación en el ambiente universitario.

“A pesar de la renovación teórico-metodológica atravesada por la disciplina histórica en las últimas décadas, -observan Ana Frega y Lina Betruccimayoritariamente los historiadores continúan utilizando las imágenes a modo de ilustración para complementar trabajos ya escritos o acompañar temas y problemas abordados a partir de otras fuentes.

Este fenómeno característico del quehacer historiográfico en general es también verificable para el caso uruguayo en particular". Si no revertimos esta situación, no tendremos posibilidades de recuperar buena parte del patrimonio histórico-social de nuestro país.

No se trata de crear algo nuevo, porque podemos recuperar las experiencias que en otras partes del mundo existen en términos de la investigación a partir de fotografías. Como dice Pérez Monfort, la fotografía ha logrado "colarse en el espacio tradicional de los documentos y ha abierto una discusión importante sobre su valor como punto de partida del conocimiento y no sólo como mera acompañante". ${ }^{10}$

Por su parte, Frega y Betrucci dicen que "su escasa consideración como documento ha retrasado el establecimiento de metodologías propias del análisis documental para decodificar y sistematizar sus soportes y contenidos", y agregan que no se ha promovido "la investigación acerca de sus partes constitutivas y sus consiguientes deterioros a raíz del paso del tiempo y de las variadas condiciones de conservación". 


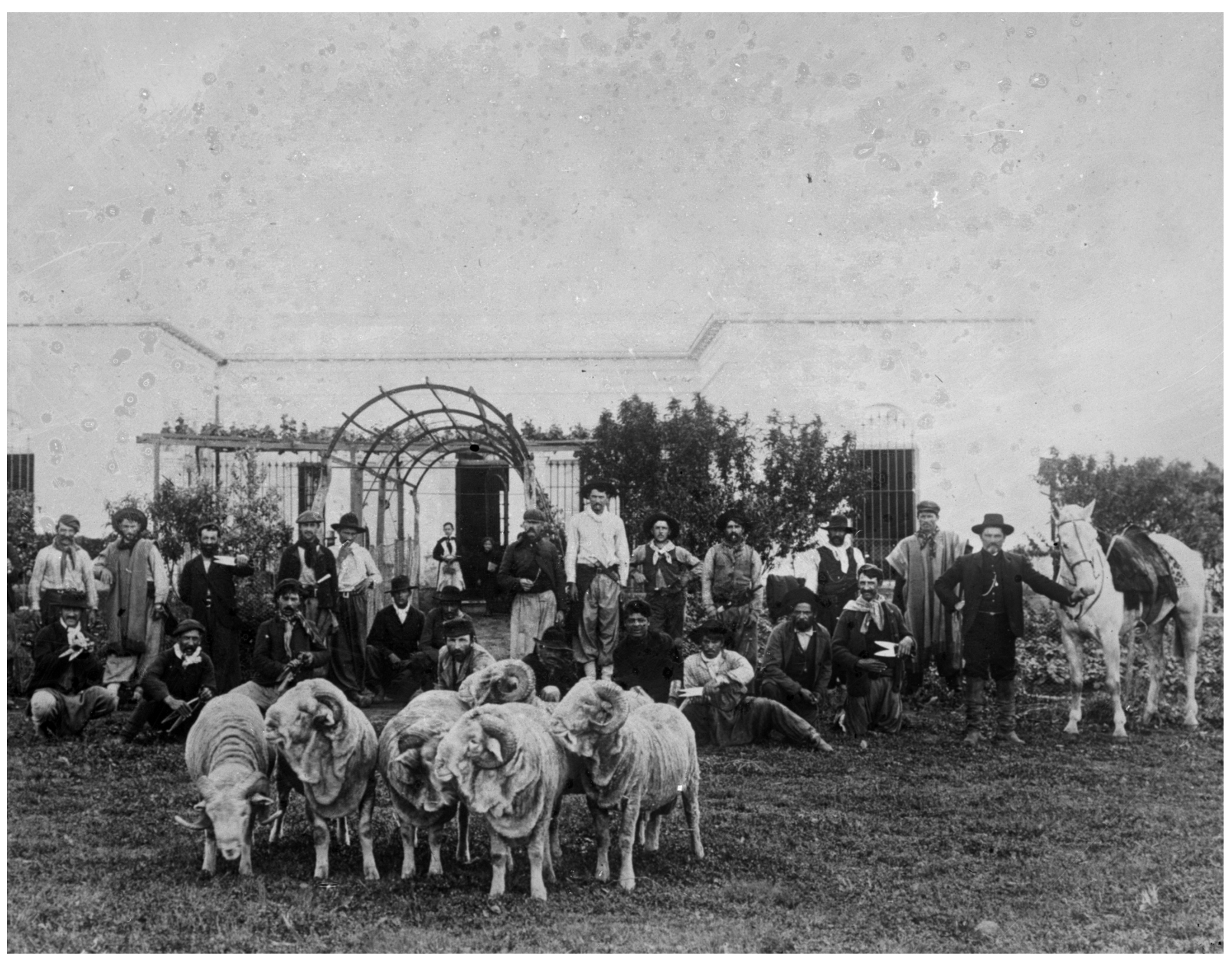

Existe un sistema propio al análisis y sistematización de las fotografías, y no es el mismo que el de otras fuentes. Hay pasos a seguir, detalles que incluir, información que recolectar, y nomenclaturas específicas para clasificar los contenidos identificados, de forma rápida y accesible para cualquier investigador.

\section{Aprender a leer fotografías}

El historiador napolitano Matteo Manfredi desarrolló una investigación acerca del fenómeno migratorio vasco en Uruguay a partir de las fotografías intercambiadas, por medio de la correspondencia familiar, entre ambas naciones. Él advierte que «las imágenes pueden asumir significados diferentes según el contexto en que se encuentran, hasta no ser entendidas para nada si las tradiciones culturales de los "lectores" no están acostumbradas a lo que ven representado en ellas». En este sentido, agrega que no se pueden interpretar históricamente las fotografías que han sido realizadas en épocas y contextos distintos del nuestro, estribándonos en nuestra cultura visual y nuestras categorías interpretativas vinculadas a ésta. Si queremos entender el significado original de las fotografías producidas en determinada época, debemos despojarnos de nuestra cultura visual para acercarnos a lo que era el punto de vista de esa época. ${ }^{12}$ Eso es lo que debemos inculcar en las nuevas generaciones; ese es el viaje que nos propone enfrentarnos a una fotografía. Un viaje a través del tiempo y del espacio hacia un instante que no se repetirá, pero que puede contar y recontar su historia de múltiples formas a múltiples receptores. Como afirma Susan Sontag, "no hay fotografía definitiva": ${ }^{13}$ siempre tendremos oportunidad de asombrarnos al encontrar algo nuevo en lo que Jacques Derrida llama un juego infinito de significaciones, ${ }^{14}$ solo hay que entrenar la mirada y darle a la imagen una oportunidad para contar su historia.:-
$12::$

M. Manfredi: Imágenes

fotografías de la comunidad vasca en Uruguay. Un nuevo enfoque analitico para estudiar la historia las costumbres y la mentalidad de los emigrantes, Nápoles, 2009. Ver http://www.euskosare.org/

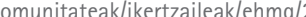
/txostenak/imagenes_fotografias comunidad_vasca_uruguay

Sontag: Al mismo tiempo. Ensayos y conferencias, Mondadori, Buenos Aires, 2007 p.138.

$14 .:$

P. Burke: op. cit. p. 224 